\title{
Mortality Rate in Veterans with Multiple Chronic Conditions
}

\author{
Todd A. Lee, $P h D^{1,2}$, Alexandra E. Shields, $P h D^{3}$, Christine Vogeli, PhD”, Teresa B. Gibson, $P h D^{4}$, \\ Min Woong-Sohn, $\mathrm{PhD}^{1,2}$, William D. Marder, $\mathrm{PhD}^{4}$, David Blumenthal, $\mathrm{MD}^{3}$, and Kevin B. Weiss, \\ $\mathrm{MD}, \mathrm{MPH}^{1,2}$
}

${ }^{1}$ Center for Management of Complex Chronic Care, Hines VA Hospital, P. O. Box 5000 (151-H), Hines, IL 60141, USA; ${ }^{2}$ Institute for Healthcare Studies and Division of General Internal Medicine, Northwestern University Feinberg School of Medicine, Chicago, IL, USA; ${ }^{3} \mathrm{Harvard}$ Medical School and Department of Medicine, Massachusetts General Hospital, Boston, MA, USA; ${ }^{4}$ Thompson MedStat, Inc, Ann Arbor, MI, USA.

\begin{abstract}
BACKGROUND: Among patients with multiple chronic conditions, there is increasing appreciation of the complex interrelatedness of diseases. Previous studies have focused on the prevalence and economic burden associated with multiple chronic conditions, much less is known about the mortality rate associated with specific combinations of multiple diseases.
\end{abstract}

OBJECTIVE: Measure the mortality rate in combinations of 11 chronic conditions.

DESIGN: Cohort study of veteran health care users.

PARTICIPANTS: Veterans between 55 and 64 years that used Veterans Health Administration health care services between October 1999 and September 2000.

MEASUREMENTS: Patients were identified as having one or more of the following: COPD, diabetes, hypertension, rheumatoid arthritis, osteoarthritis, asthma, depression, ischemic heart disease, dementia, stroke, and cancer. Mutually exclusive combinations of disease based on these conditions were created, and 5-year mortality rates were determined.

RESULTS: There were 741,847 persons included. The number in each group by a count of conditions was: none $=$ 217,944 (29.34\%); $1=221,111$ (29.8\%); $2=175,228$ (23.6\%); $3=86,447$ (11.7\%); and 4+=41,117 (5.5\%). The 5 -year mortality rate by the number of conditions was: none $=4.1 \% ; 1=6.0 \% ; 2=7.8 \% ; 3=11.2 \% ; 4+=16.7 \%$. Among combinations with the same number of conditions, there was significant variability in mortality rates.

CONCLUSIONS: Patients with multiple chronic conditions have higher mortality rates. Because there was significant variation in mortality across clusters with the same number of conditions, when studying patients with multiple coexisting illnesses, it is important to understand not only that several conditions may be present but that specific conditions can differentially impact the risk of mortality.

KEY WORDS: chronic conditions; coexistant conditions; mortality; veterans J Gen Intern Med 22(Suppl 3):403-7

DOI: $10.1007 / \mathrm{s} 11606-007-0277-2$

(C) Society of General Internal Medicine 2007

\section{INTRODUCTION}

Diseases are often described and studied as if they occur in isolation of other disease states, yet many individuals have multiple chronic conditions. Cooccurrence of various chronic conditions can have unexpected consequences on disability, ${ }^{1}$ lead to deficiencies in care, ${ }^{2}$ and impact the benefit of clinical practice guidelines. ${ }^{3}$ Yet, little is known about the overall impact on mortality of specific combinations of chronic conditions.

The increasing prevalence of multiple coexisting chronic diseases with age is a phenomenon that makes sense from a biological and clinical basis and has been described by several investigators. For example, in The Netherlands, more than $60 \%$ of persons between 60 and 79 years old have more then one chronic condition, and the average number of chronic conditions in this group is $2.4 .^{4}$ In the United States, for persons older than 65 years, the average number of chronic conditions is 2.3 , and the prevalence of persons with more than one chronic condition is $64.7 \% .^{5}$ In addition, patients with more chronic conditions have higher health care expenditures. Again, in persons in the United States over 65 years of age, the average annual expenditures for those with four or more chronic conditions was $\$ 13,973$, and among those with three chronic conditions, expenditures were $\$ 4,701 .^{5}$ For persons receiving care through the Veterans Health Administration (VHA), the average annual cost was $\$ 9,277$ for those with three or more chronic conditions and was $\$ 3,366$ in those with two chronic conditions. ${ }^{6}$ These studies show that there is a substantial proportion of older patients that have multiple chronic conditions, and these patients have higher health care expenditures.

It remains unclear whether there are specific disease groups or clusters that are associated with increased risk of mortality among persons with multiple chronic diseases. There are several recent examples of how the Charlson index and other risk indices, as well as identification of individual diseases, have been used to successfully predict mortality. ${ }^{7-16}$ In addition, we generally know how individual diseases increase the risk of mortality, but whether specific combinations of diseases have an additive or multiplicative effect on overall mortality when present with other chronic diseases is not well understood. The objective of this study was to describe the 5 -year mortality rates across patients with multiple chronic conditions. 


\section{MATERIALS AND METHODS}

The national Veterans Affairs (VA) inpatient, outpatient, and mortality databases were used to conduct a cohort study to examine the risk of mortality associated with clusters of chronic diseases. The study population was US veterans using the VHA health care system between the age of 55 and 64 years. As of April 2000, there were approximately 4.4 million veterans that received health care services through VHA. ${ }^{17}$ The VHA maintains databases of all encounters for patients receiving care in the VHA health care system or through contract services with other providers. We used care provided at VHA facilities as well as care provided through contracted services to identify chronic conditions for patients included in this analysis. Information on inpatient admissions, outpatient encounters, and dates of death are available in the databases.

\section{Cohort}

The cohort used in the analysis was all veterans with at least one health care contact with the VA system between October 1, 1999 and September 30, 2000. Veterans between the ages of 55 and 64 years of age during this 12-month period were included in the analysis. The cohort was followed until September 30, 2004.

\section{Disease Clusters}

Patients were identified as having one or more of the following conditions based on ICD-9 codes: COPD, diabetes, hypertension, rheumatoid arthritis, osteoarthritis, asthma, depression, ischemic heart disease, dementia, stroke, and cancer. These chronic diseases were chosen based on the list of priority conditions-conditions that are prevalent and high cost in the United States-from the Agency for Health care Research and Quality (AHRQ) and the Centers for Medicare and Medicaid Services (CMS). The ICD-9 codes used to identify the conditions were based on the AHRQ Clinical Classification System (Appendix). ${ }^{18}$

Based on inpatient and outpatient encounters within the VA health care system in 2000 , patients were categorized into mutually exclusive groups of chronic diseases. Persons were defined as having one of the chronic conditions if they had any diagnosis code for the condition during the 1-year time period. The diagnostic codes were combined to create mutually exclusive combinations of the chronic diseases so that persons would only be included in one chronic disease combination. Persons without a diagnosis for any of the conditions were categorized into a "none of the selected conditions" group.

\section{Mortality}

Deaths occurring during the 5-year period following identification of the cohort were determined. Both inpatient data and the Beneficiary Identification and Records Locator System (BIRLS) data were used to identify all deaths that occurred during the follow-up period. The BIRLS data have been reported to capture between 90 and $95 \%$ of veterans that die. ${ }^{19,20}$ Date of death was assigned on the basis of discharge date for deaths that occurred in the hospital. For deaths not identified in the inpatient data, the date of death was the date reported in the BIRLS database.
Table 1. Five-Year Mortality Rate Among Patients with only a Single Condition or None of the Conditions

\begin{tabular}{|c|c|c|c|c|}
\hline & \multicolumn{4}{|c|}{ 5-year mortality rate } \\
\hline & Number & $\begin{array}{l}\text { Crude } \\
(\%)\end{array}$ & $\begin{array}{l}\text { Age } \\
\text { adjusted } \\
(\%)\end{array}$ & $95 \% \mathrm{Cl}(\%)$ \\
\hline Osteoarthritis & 25,231 & 2.75 & 2.77 & $(2.56,2.97)$ \\
\hline Asthma & 3,399 & 3.18 & 3.13 & $(2.54,3.71)$ \\
\hline Hypertension & 107,732 & 3.81 & 3.81 & $(3.70,3.93)$ \\
\hline $\begin{array}{l}\text { None of the } \\
\text { selected conditions }\end{array}$ & 217,944 & 4.11 & 4.14 & $(4.06,4.22)$ \\
\hline Depression & 10,922 & 4.38 & 4.66 & $(4.19,5.13)$ \\
\hline $\begin{array}{l}\text { Rheumatoid } \\
\text { arthritis }\end{array}$ & 1,694 & 5.96 & 6.05 & $(4.90,7.20)$ \\
\hline $\begin{array}{l}\text { Ischemic heart } \\
\text { disease }\end{array}$ & 16,898 & 6.18 & 6.18 & $(5.81,6.54)$ \\
\hline Diabetes & 24,158 & 7.06 & 7.07 & $(6.75,7.39)$ \\
\hline Stroke & 2,023 & 9.34 & 9.24 & $(7.99,10.50)$ \\
\hline COPD & 15,540 & 13.15 & 13.08 & $(12.55,13.61)$ \\
\hline Dementia & 2,197 & 14.75 & 15.07 & $(13.55,16.60)$ \\
\hline Cancer & 10,489 & 22.26 & 22.46 & $(21.65,23.26)$ \\
\hline
\end{tabular}

\section{Analysis}

Patients were classified into mutually exclusive disease clusters based on their diagnosis codes during the initial 12-month period. The proportion of patients in each mutually exclusive cluster was determined. Patients were grouped into the following categories according to the number of diseases in their cluster: none; one; two; three; or four or more.

We present data in the tables for clusters that included more than 1,000 patients. The cumulative 5-year mortality rates and $95 \%$ confidence intervals were determined for each cluster and for the four categories based on a count of the number of diseases in a cluster. Cumulative 5-year mortality rates were adjusted for age by standardizing each cluster to the age of the overall cohort.

\section{RESULTS}

A total of 741,847 patients between 55 and 64 years had at least one VA health care encounter between October 1, 1999 and September 30, 2000. There were two groups combined that contained $43.9 \%$ of the population. There were 217,944 (29.4\%) patients identified as not having any of the selected conditions and 107,732 (14.5\%) identified as having hypertension and none of the other selected conditions. The top five two cluster groupings all included hypertension as one of the conditions and were: hypertension+diabetes (6.4\%); heart disease+hypertension (3.8\%); hypertension+osteoarthritis $(3.2 \%)$; hypertension + COPD (1.6\%); and cancer+hypertension (1.0\%). Among those conditions with more than 1,000 persons, hypertension was one of the conditions in each of the clusters that included three or four conditions.

When grouping the clusters by the number of conditions, the majority of the patients included in this analysis had either none of the selected conditions $(29.4 \%)$ or only a single condition by itself (29.8\%). Thus, there was $40.8 \%$ of the population that had a cluster of diseases (i.e., two or more conditions), with a decreasing proportion in each group as the number of conditions increased (two conditions $=23.6 \%$; three conditions $=11.7 \%$; four or more conditions $=5.5 \%$ ). 
Table 2. Five-Year Mortality Rate Among Patients with Two Conditions

\begin{tabular}{|c|c|c|c|c|}
\hline \multirow[t]{2}{*}{ Cluster } & \multicolumn{4}{|c|}{ 5-year mortality rate } \\
\hline & Number & $\begin{array}{l}\text { Crude } \\
(\%)\end{array}$ & $\begin{array}{l}\text { Age } \\
\text { adjusted (\%) }\end{array}$ & $95 \% \mathrm{Cl}(\%)$ \\
\hline Hypertension and osteoarthritis & 2,088 & 2.94 & 2.94 & $2.72,3.15$ \\
\hline Depression and osteoarthritis & 23,692 & 2.83 & 3.03 & $2.18,3.88$ \\
\hline Asthma and hypertension & 2,418 & 3.39 & 3.34 & $2.62,4.05$ \\
\hline Ischemic heart disease and osteoarthritis & 2,845 & 3.87 & 3.81 & $3.11,4.52$ \\
\hline Diabetes and osteoarthritis & 3,652 & 4.85 & 4.84 & $4.15,5.54$ \\
\hline Hypertension and rheumatoid arthritis & 1,144 & 4.90 & 4.91 & $3.66,6.16$ \\
\hline Depression and hypertension & 6,410 & 5.16 & 5.44 & $4.81,6.06$ \\
\hline Hypertension and ischemic heart disease & 28,154 & 5.58 & 5.66 & $5.38,5.93$ \\
\hline Diabetes and hypertension & 47,568 & 6.28 & 6.28 & $6.07,6.50$ \\
\hline Depression and diabetes & 1,440 & 6.46 & 6.50 & $5.12,7.88$ \\
\hline Depression and ischemic heart disease & 1,030 & 6.50 & 6.91 & $5.26,8.56$ \\
\hline Asthma and COPD & 1,576 & 7.99 & 8.04 & $6.70,9.38$ \\
\hline Hypertension and stroke & 3,679 & 8.70 & 8.75 & $7.83,9.68$ \\
\hline COPD and osteoarthritis & 3,106 & 9.53 & 9.49 & $8.46,10.52$ \\
\hline Diabetes and ischemic heart disease & 1,274 & 11.40 & 11.38 & $10.56,12.21$ \\
\hline Depression and COPD & 5,790 & 11.07 & 11.60 & $9.70,13.49$ \\
\hline COPD and hypertension & 11,883 & 12.22 & 12.14 & $11.55,12.74$ \\
\hline Cancer and osteoarthritis & 1,338 & 12.26 & 12.29 & $10.51,14.06$ \\
\hline Dementia and hypertension & 1,203 & 12.88 & 12.88 & $11.00,14.76$ \\
\hline COPD and ischemic heart disease & 7,235 & 15.59 & 15.03 & $13.76,16.29$ \\
\hline Cancer and hypertension & 3,060 & 14.93 & 15.36 & $14.49,16.24$ \\
\hline Diabetes and COPD & 1,704 & 16.61 & 16.56 & $14.78,18.34$ \\
\hline Cancer and ischemic heart disease & 1,023 & 21.70 & 22.60 & $19.84,25.36$ \\
\hline Cancer and diabetes & 1,253 & 24.34 & 24.90 & $22.45,27.35$ \\
\hline Cancer and COPD & 1,860 & 39.84 & 40.41 & $38.07,42.75$ \\
\hline
\end{tabular}

A total of 52,306 patients died during the 5-year follow-up period, which equates to an overall 5-year mortality rate of $7.1 \%$. The mortality rate was lowest among those with none of the selected diseases (4.1\%) and increased as the number of conditions increased. Compared to patients with none of the selected conditions, the risk of death during the follow-up period for each of the other groups was: one condition risk ratio $(\mathrm{RR})=1.45(95 \% \mathrm{CI}, 1.41-1.49)$; two conditions $\mathrm{RR}=1.88(95 \%$ CI, 1.83-1.93); three conditions $\mathrm{RR}=2.72$ (95\% CI, 2.65-2.80); and four or more conditions $\mathrm{RR}=4.07$ (95\% CI, 3.95-4.19).

Among those identified with only a single condition, there was nearly a tenfold difference in the lowest to highest mortality rate. The age-adjusted, 5-year mortality rate ranged from $2.77 \%$ for osteoarthritis to $22.46 \%$ for cancer (Table 1 ). There were a total of 23 clusters that included only two conditions. The age-adjusted, 5-year mortality rate among the two condition clusters ranged from $2.94 \%$ for hypertension+osteoarthritis to $40.41 \%$ for cancer+COPD (Table 2). Interestingly, when osteoarthritis was present in a two-condition group, the 5-year mortality rate was lower in the twocondition cluster than the mortality rate in the condition by itself. For example, the 5-year mortality rate for individuals with hypertension alone was $3.81 \%$, whereas in those with hypertension and osteoarthritis, the rate was $2.94 \%$. Not surprisingly, the presence of cancer in a cluster was associated with higher 5-year mortality rates, of the three two-condition clusters with a mortality greater than $20 \%$, each of them included cancer as one of the conditions.

Similar to the two-condition clusters, there was significant variability in the 5-year mortality rate among the threecondition clusters. The 5-year mortality rate ranged from $4.2 \%$ for hypertension+depression+osteoarthritis to $34.6 \%$ for cancer+hypertension + COPD (Table 3). Among those con- ditions with mortality rates greater than $15 \%$, each included either COPD or cancer as one of the conditions.

There were seven four-condition clusters that included more than 1,000 individuals. Each of the clusters included ischemic heart disease, whereas all but one included hypertension, and all but two included diabetes. The 5 -year mortality rate ranged from $9.4 \%$ for ischemic heart disease+hypertension+diabetes+ osteoarthritis to $22.3 \%$ for ischemic heart disease+hypertension+ diabetes+COPD (Table 4). For the clusters that included ischemic heart disease, hypertension, and diabetes, the fourth condition in the cluster influences the overall 5-year mortality rate. The mortality rates for these clusters with respect to the fourth condition were: osteoarthritis $=9.4 \%$, depression= $12.7 \%$, stroke $=16.8 \%$; cancer $=22.0 \%$; and $\mathrm{COPD}=22.3 \%$.

\section{DISCUSSION}

In this analysis, we found that the presence of chronic conditions in veterans between the ages of 55 and 64 years is high, and a significant number of these individuals have two or more conditions. Not surprisingly, the presence of more conditions was associated with a higher risk of 5-year mortality. However, there was a wide range in the mortality rates across clusters with the same number of conditions, indicating the presence of specific diseases within a cluster impacted the risk of 5-year mortality differently.

Previous studies, both on a veteran $\operatorname{cohort}^{6}$ and on a sample of the general U.S. population, ${ }^{5}$ found that costs increased dramatically as the number of chronic conditions increased. These previous studies did not look at the risk of mortality associated with chronic conditions. We found a similar pattern with respect to mortality in that as the number of chronic conditions 
Table 3. Five-Year Mortality Rate Among Patients with Three Conditions

\begin{tabular}{|c|c|c|c|c|}
\hline \multirow[t]{2}{*}{ Cluster } & \multicolumn{4}{|c|}{5 -year mortality rate } \\
\hline & Number & $\begin{array}{l}\text { Crude } \\
(\%)\end{array}$ & $\begin{array}{l}\text { Age } \\
\text { adjusted } \\
(\%)\end{array}$ & $\begin{array}{l}95 \% \mathrm{Cl} \\
(\%)\end{array}$ \\
\hline $\begin{array}{l}\text { Hypertension and } \\
\text { depression and } \\
\text { osteoarthritis }\end{array}$ & 1,959 & 3.88 & 4.16 & $\begin{array}{l}3.16 \\
5.16\end{array}$ \\
\hline $\begin{array}{l}\text { Ischemic heart disease } \\
\text { and hypertension and } \\
\text { osteoarthritis }\end{array}$ & 5,945 & 4.61 & 4.52 & $\begin{array}{r}3.99 \\
5.05\end{array}$ \\
\hline $\begin{array}{l}\text { Hypertension and } \\
\text { diabetes and } \\
\text { osteoarthritis }\end{array}$ & 9,136 & 5.32 & 5.30 & $\begin{array}{r}4.84 \\
5.76\end{array}$ \\
\hline $\begin{array}{l}\text { Ischemic heart disease } \\
\text { and hypertension and } \\
\text { depression }\end{array}$ & 1,866 & 7.34 & 7.66 & $\begin{array}{r}6.40 \\
8.92\end{array}$ \\
\hline $\begin{array}{l}\text { Hypertension and } \\
\text { diabetes and } \\
\text { depression }\end{array}$ & 2,782 & 7.84 & 8.17 & $\begin{array}{c}7.06 \\
9.27\end{array}$ \\
\hline $\begin{array}{l}\text { Hypertension and } \\
\text { COPD and asthma }\end{array}$ & 1,159 & 8.28 & 8.36 & $\begin{array}{c}6.75 \\
9.97\end{array}$ \\
\hline $\begin{array}{l}\text { Hypertension and } \\
\text { COPD and } \\
\text { osteoarthritis }\end{array}$ & 3,073 & 9.24 & 9.18 & $\begin{array}{l}8.15 \\
10.20\end{array}$ \\
\hline $\begin{array}{l}\text { Cancer and } \\
\text { hypertension and } \\
\text { osteoarthritis }\end{array}$ & 1,433 & 9.49 & 9.40 & $\begin{array}{l}7.82 \\
10.99\end{array}$ \\
\hline $\begin{array}{l}\text { Ischemic heart disease } \\
\text { and stroke and } \\
\text { hypertension }\end{array}$ & 2,025 & 10.47 & 10.49 & $\begin{array}{l}9.11 \\
11.87\end{array}$ \\
\hline $\begin{array}{l}\text { Ischemic heart disease } \\
\text { and hypertension and } \\
\text { diabetes }\end{array}$ & 19,161 & 11.13 & 11.10 & $\begin{array}{r}10.65 \\
11.55\end{array}$ \\
\hline $\begin{array}{l}\text { Stroke and } \\
\text { hypertension and } \\
\text { diabetes }\end{array}$ & 2,133 & 12.56 & 12.72 & $\begin{array}{l}11.29 \\
14.16\end{array}$ \\
\hline $\begin{array}{l}\text { Ischemic heart disease } \\
\text { and hypertension and } \\
\text { COPD }\end{array}$ & 5,556 & 14.67 & 14.46 & $\begin{array}{c}13.52 \\
15.40\end{array}$ \\
\hline $\begin{array}{l}\text { Hypertension and } \\
\text { diabetes and COPD }\end{array}$ & 3,687 & 15.30 & 15.20 & $\begin{array}{c}14.02 \\
16.37\end{array}$ \\
\hline $\begin{array}{l}\text { Ischemic heart disease } \\
\text { and cancer and } \\
\text { hypertension }\end{array}$ & 1,804 & 16.74 & 17.65 & $\begin{array}{l}15.70 \\
19.60\end{array}$ \\
\hline $\begin{array}{l}\text { Cancer and } \\
\text { hypertension and } \\
\text { diabetes }\end{array}$ & 2,809 & 17.84 & 18.05 & $\begin{array}{c}16.53 \\
19.58\end{array}$ \\
\hline $\begin{array}{l}\text { Cancer and } \\
\text { hypertension and } \\
\text { COPD }\end{array}$ & 1,360 & 33.97 & 34.62 & $\begin{array}{c}31.84 \\
37.40\end{array}$ \\
\hline
\end{tabular}

increased, the 5-year mortality rates also increased for patients with three or four chronic conditions. It was also apparent that combining the conditions by simply using a count of the number of conditions results in substantial loss of information regarding the outcomes of patients with multiple chronic conditions. That is, not all clusters of two conditions were equivalent, and the risk of mortality was highly dependent on the conditions that comprised the clusters. Therefore, when examining persons with multiple coexisting conditions, it is important to understand the components of a cluster, and it may be misleading to combine groups based on the number of chronic conditions.

Unlike the previous work examining multiple chronic conditions, ${ }^{5,6}$ we focused on a limited number of chronic conditions. Where Yu et al. ${ }^{6}$ included 29 conditions, and Wolff et al. ${ }^{5}$ used 24 categories of diagnostic groups, we chose to
Table 4. Five-Year Mortality Rate Among Patients with Four Conditions

\begin{tabular}{|c|c|c|c|c|}
\hline \multirow[t]{2}{*}{ Cluster } & \multicolumn{4}{|c|}{5 -year mortality rate } \\
\hline & Number & $\begin{array}{l}\text { Crude } \\
\text { (\%) }\end{array}$ & $\begin{array}{l}\text { Age } \\
\text { adjusted } \\
\text { (\%) }\end{array}$ & $\begin{array}{l}95 \% \mathrm{Cl} \\
(\%)\end{array}$ \\
\hline $\begin{array}{l}\text { Ischemic heart disease } \\
\text { and hypertension and } \\
\text { diabetes and } \\
\text { osteoarthritis }\end{array}$ & 3,821 & 9.40 & 9.37 & $\begin{array}{l}8.42, \\
10.31\end{array}$ \\
\hline $\begin{array}{l}\text { Ischemic heart disease } \\
\text { and hypertension and } \\
\text { COPD and } \\
\text { osteoarthritis }\end{array}$ & 1,550 & 11.81 & 11.66 & $\begin{array}{c}10.03 \\
13.30\end{array}$ \\
\hline $\begin{array}{l}\text { Hypertension and } \\
\text { diabetes and COPD and } \\
\text { osteoarthritis }\end{array}$ & 1,073 & 12.40 & 12.23 & $\begin{array}{c}10.25 \\
14.20\end{array}$ \\
\hline $\begin{array}{l}\text { Ischemic heart disease } \\
\text { and hypertension and } \\
\text { diabetes and depression }\end{array}$ & 1,506 & 12.48 & 12.67 & $\begin{array}{c}10.95 \\
14.39\end{array}$ \\
\hline $\begin{array}{l}\text { Ischemic heart disease } \\
\text { and hypertension and } \\
\text { diabetes and stroke }\end{array}$ & 1,850 & 16.97 & 16.77 & $\begin{array}{r}15.03 \\
18.52\end{array}$ \\
\hline $\begin{array}{l}\text { Ischemic heart disease } \\
\text { and hypertension and } \\
\text { diabetes and cancer }\end{array}$ & 1,142 & 22.24 & 21.56 & $\begin{array}{r}18.96 \\
24.15\end{array}$ \\
\hline $\begin{array}{l}\text { Ischemic heart disease } \\
\text { and hypertension and } \\
\text { diabetes and COPD }\end{array}$ & 3,204 & 22.38 & 22.33 & $\begin{array}{r}20.86 \\
23.81\end{array}$ \\
\hline
\end{tabular}

focus on 11 major conditions in creating our clusters of diseases. The conditions we included are high prevalence and high cost conditions in the United States and as such represent high priority conditions for health care agencies. Expansion of our list from these 11 conditions would have resulted in a larger number of total clusters that patients could have fallen into (there were 1,348 unique disease groups with at least one patient in this analysis) and would have also reduced the sample size in each of the clusters. However, by focusing only on these conditions, we are essentially ignoring the impact of other conditions that the patient may have and that could affect both costs and the risk of mortality. For example, if a condition occurred more frequently with one of the conditions included in this analysis, we would be picking up the effect of the condition that we measured as well as the unmeasured condition.

There are other limitations to our analysis, one of which is the fact that the classification of individuals into chronic disease clusters was based on ICD-9 codes available at the inception of the cohort, and subsequent development of disease during the 5-year follow-up was not incorporated into the analysis. As noted above, we did not consider other conditions in creating our disease clusters nor did we use other diseases as risk adjusters. We confined our analysis to veterans between 55 and 64 years to limit the effects of age on outcomes and to use a population that was not yet eligible to receive Medicare services. Therefore, the results are most generalizable to males in this age range, and findings could be substantially different for females and other ages. Only diagnoses that were associated with a VA encounter or VA contracted services were used in the analysis, and thus, if veterans were receiving care outside of the system, these diagnoses were not captured. Finally, because we rely on administrative data from a single year to characterize our cohort, we are unable to accurately capture the duration and severity of 
disease and the validity of ICD-9 codes in identifying diseases likely varies. The risk of mortality within the selected age group may be modified by the duration of disease, which is not accounted for in this analysis. For example, the effect of diabetes on mortality in persons included in this analysis may be very different if the diabetes developed when the patient was 40 years old compared to when they were 60 years old. In addition, if severity of disease is associated with the presence of more conditions, the increase in risk of mortality would be because of a combination of disease severity and other conditions.

We found that patients with multiple chronic conditions in the VA health care system represent a significant proportion of VA patients and have an increased risk for mortality. Not surprisingly, more conditions were associated with higher rates of mortality; however, there was significant variation in clusters with the same number of diseases. Thus, when studying patients with multiple coexisting illnesses, it is important to understand not only that several conditions may be present but that the specific conditions can differentially impact the risk of mortality.

Acknowledgments: This research was supported in part by grant no. IIR 03-307 from the Department of Veterans Affairs Health Services Research and Development.

Conflict of interest: None disclosed.

Corresponding Author: Todd A. Lee, PhD; Center for Management of Complex Chronic Care, Hines VA Hospital, P. O. Box 5000 (151-H), Hines, IL 60141, USA (e-mail: todd.lee@va.gov).

\section{APPENDIX}

Table 5. ICD-9 Codes Included in Definition of Chronic Diseases

\begin{tabular}{|c|c|}
\hline $\begin{array}{l}\text { Chronic } \\
\text { condition }\end{array}$ & Eligible ICD-9 codes \\
\hline Asthma & 493.x,494.x \\
\hline Cancer & $\begin{array}{l}\text { 140.x, 141.x, 142.x, 143.x, 144.x, 145.x, 146.x, } 147 . \\
\text { x, 148.x, 149.x, 150.x, 151.x, 152.x, 153.x, 154.x, } \\
\text { 155.x, 156.x, 157.x, 158.x, 159.0, 160.x, 161.x, } 162 . \\
\text { x, 170.x, 171.x, 174.x, 175.x, 179, 180.x, 182.x, } \\
\text { 185, 186.0, 186.9, 188.x, 189.0, 189.1, 191.x, } 192 . \\
\text { x, 195.0, 230.x, 231.x, 233.x, V10.xx }\end{array}$ \\
\hline COPD & 491.x, 492.x, 496 \\
\hline Dementia & $\begin{array}{l}\text { 290.x, 293.x, 294.x, 310.x, 331.0, 331.1, 331.1x } \\
\text { 331.2, 331.82, 797 }\end{array}$ \\
\hline Depression & $296.2 x, 296.3 x, 300.4$ \\
\hline Diabetes & 250.x, 790.2x, 791.5, 791.6, V45.85, V53.91, V65.46 \\
\hline Hypertension & $\begin{array}{c}401.1,401.9,401.0,402 . x, 403 . x, 404 . x, 405.01 \\
405.09,405.11,405.19,405.91,405.99,437.2\end{array}$ \\
\hline $\begin{array}{l}\text { Ischemic } \\
\text { heart } \\
\text { disease }\end{array}$ & $\begin{array}{l}\text { 410.x, 411.0, 411.1, 411.8x, 412, 413.0, 413.1, } \\
\text { 413.9, 414.x, V45.81, V45.82 }\end{array}$ \\
\hline Osteoarthritis & 715.x \\
\hline $\begin{array}{l}\text { Rheumatoid } \\
\text { arthritis }\end{array}$ & $714,714.0$ \\
\hline Stroke & 430, 431, 432.x, 433.x, 434.x, 435.x, 436 \\
\hline
\end{tabular}

\section{REFERENCES}

1. Fried LP, Bandeen-Roche K, Kasper JD, Guralnik JM. Association of comorbidity with disability in older women: the Women's Health and Aging Study. J Clin Epidemiol. 1999;52:27-37.

2. Redelmeier DA, Tan SH, Booth GL. The treatment of unrelated disorders in patients with chronic medical diseases. N Engl J Med. 1998;338: 1516-20.

3. Boyd CM, Darer J, Boult C, Fried LP, Boult L, Wu AW. Clinical practice guidelines and quality of care for older patients with multiple comorbid diseases: implications for pay for performance. JAMA. 2005;294:716-24.

4. van den AM, Buntinx F, Metsemakers JF, Roos S, Knottnerus JA. Multimorbidity in general practice: prevalence, incidence, and determinants of co-occurring chronic and recurrent diseases. J Clin Epidemiol. 1998;51:367-75.

5. Wolff JL, Starfield B, Anderson G. Prevalence, expenditures, and complications of multiple chronic conditions in the elderly. Arch Intern Med. 2002;162:2269-76.

6. Yu W, Ravelo A, Wagner TH, Phibbs CS, Bhandari A, Chen S et al. Prevalence and costs of chronic conditions in the VA health care system. Med Care Res Rev. 2003;60:146S-67S.

7. Kurichi JE, Stineman MG, Kwong PL, Bates BE, Reker DM. Assessing and using comorbidity measures in elderly veterans with lower extremity amputations. Gerontology. 2007;53:255-59.

8. Thombs BD, Singh VA, Halonen J, Diallo A, Milner SM. The effects of preexisting medical comorbidities on mortality and length of hospital stay in acute burn injury: evidence from a national sample of 31,338 adult patients. Ann Surg. 2007;245:629-34.

9. Chirinos JA, Veerani A, Zambrano JP, Schob A, Perez G, Mendez AJ et al. Evaluation of comorbidity scores to predict all-cause mortality in patients with established coronary artery disease. Int $\mathrm{J}$ Cardiol. 2007; 117:97-102.

10. Murray SB, Bates DW, Ngo L, Ufberg JW, Shapiro NI. Charlson Index is associated with one-year mortality in emergency department patients with suspected infection. Acad Emerg Med. 2006;13:530-536.

11. Schroeder RA, Marroquin CE, Bute BP, Khuri S, Henderson WG, Kuo PC. Predictive indices of morbidity and mortality after liver resection. Ann Surg. 2006;243:373-79.

12. Hall WH, Jani AB, Ryu JK, Narayan S, Vijayakumar S. The impact of age and comorbidity on survival outcomes and treatment patterns in prostate cancer. Prostate Cancer Prostatic Dis. 2005;8:22-30.

13. Soares M, Salluh JI, Ferreira CG, Luiz RR, Spector N, Rocco JR. Impact of two different comorbidity measures on the 6-month mortality of critically ill cancer patients. Intensive Care Med. 2005;31:408-15.

14. Sundararajan V, Henderson T, Perry C, Muggivan A, Guan H, Ghali WA. New ICD-10 version of the Charlson comorbidity index predicted inhospital mortality. J Clin Epidemiol. 2004;57:1288-94.

15. Perkins AJ, Kroenke K, Unutzer J, Katon W, Williams JW, Hope C, et al. Common comorbidity scales were similar in their ability to predict health care costs and mortality. J Clin Epidemiol. 2004;57:1040-48.

16. Nagel G, Wedding U, Rohrig B, Katenkamp D. The impact of comorbidity on the survival of postmenopausal women with breast cancer. J Cancer Res Clin Oncol. 2004;130:664-70.

17. Cowper, D. C., Ripley, B. A., Kuebeler, M. K., Yu, W., Kubal, J. D., Manheim, L. M. VA health care atlas, FY-2000. Rehabilitation Outcomes Research Center, Department of Veterans Affairs. 2003. Available at: http://wwwl.va.gov/rorc/products.cfm Last accessed: 6-20-2007.

18. HCUP Clinical Classification Software (CCS) for ICD-9-CM. Healthcare Cost and Utilization Project (HCUP). 8-22-2005. Agency for Healthcare Research and Quality, Rockville, MD. Available at: http:// www.hcup-us.ahrq.gov/toolssoftware/ccs/ccs.jsp Last accessed: 6-202007.

19. Page WF, Braun MM, Caporaso NE. Ascertainment of mortality in the U. S. veteran population: World War II veteran twins. Mil Med. 1995; 160:351-55.

20. Page WF, Mahan CM, Kang HK. Vital status ascertainment through the files of the Department of Veterans Affairs and the Social Security Administration. Ann Epidemiol. 1996;6:102-9. 